\title{
Quality of life of women with breast cancer
} undergoing radiotherapy using the Functional Assessment of Chronic Illness Therapy-Fatigue questionnaire

\author{
This article was published in the following Dove Press journal: \\ Clinical Interventions in Aging \\ 20 October 2016 \\ Number of times this article has been viewed
}

\author{
Marta Muszalik' \\ Małgorzata Kołucka-Pluta ${ }^{2}$ \\ Kornelia Kędziora- \\ Kornatowska' \\ Joanna Robaczewska'
}

'Department and Clinic of Geriatrics, Nicolaus Copernicus University, Collegium Medicum in Bydgoszcz, ${ }^{2}$ Centrum of Oncology in Bydgoszcz, Bydgoszcz, Poland
Correspondence: Marta Muszalik

Clinic of Geriatrics, Nicolaus Copernicus University, Collegium Medicum in

Bydgoszcz, M Sklodowska-Curie 9 street, 85-094 Bydgoszcz, Poland

Tel +48 525854900

Email muszalik@cm.umk.pl
Objective: Breast cancer is one of the most common cancers in women, particularly among older women. This illness along with its treatment has a great impact on a woman's subjective opinion of her quality of life and functioning in everyday life. The aim of this research was to assess the quality of life in women undergoing radiotherapy for the treatment of breast cancer.

Patients and methods: The research was carried out in 120 patients with breast cancer undergoing radiotherapy in the Oncological Center in Bydgoszcz, Poland. Among the 120 examined patients, there were 30 women aged between $20-50$ years and the remaining were over 50 years of age, including 42 women over the age of 60 . Demographic and clinical data were collected and the Functional Assessment of Chronic Illness Therapy-Fatigue questionnaire (version 4) was used to assess health-related quality of life (HRQOL) of the patients. Statistical analyses were conducted using Statistica, version 10.0.

Results: Patients with breast cancer undergoing radiotherapy rated their quality of life with an average of 113.83 points. Older patients above 71 years of age also displayed significantly higher HRQOL (122.70 points). A lower level of fatigue was noticed among patients $\leq 50$ years and $\geq 71$ years of age. Education and marital status also had an important impact on HRQOL. Educated women with a good financial situation had a significantly higher HRQOL, compared to those with a lower education and in poor living conditions.

Conclusion: HRQOL and state of fatigue in breast cancer patients treated with radiotherapy depended upon their age. Both were high among women aged 71 years and above, while younger patients (51-70 years of age) had slightly lower values. Results suggest that sociodemographic factors influence the conditions of life of women treated with radiotherapy for breast cancer in a significant way. Overall, patients tolerated this type of treatment well.

Keywords: quality of life, breast cancer, elderly women, radiotherapy, HRQOL, FACIT-F

\section{Introduction}

Despite the modern advances in prevention, technology, and treatment, cancer is still being considered one of the greatest health problems of the 21 st century. In Poland, breast cancer is the most common malignant cancer.

The increase in mortality had persisted in Poland until the mid-1980s, followed by stabilization of rates at the level of $15-16 / 10^{5}$. Since the mid-1990s of the last century, there has been a decrease in mortality due to breast cancer. ${ }^{1}$

Worldwide, approximately 34\% of women suffer from breast cancer. In Poland, in 2011 , approximately $22.8 \%$ of women had breast cancer and $13.4 \%$ of them died. 
Recently, there has been a $4 \%-5 \%$ growth in its incidence. Age at onset of disease is 60-64 years among women. ${ }^{2}$

Early detection of breast cancer gives the greatest chance to overcome the disease. Health promotion and education of all those undergoing preventive examinations is particularly important. Breast cancer and its treatment interfere significantly with different spheres of a woman's life and perturb functioning. A vast majority of women with breast cancer try to deal with a new situation using various methods and strategies. Modern medicine is seeking new possibilities to provide the highest standards of living for women with breast cancer. Given the recent changes in biomedical and holistic models of care, control of quality of life is of particular interest. Accepting one's health helps to get involved in active treatment and recuperation. In medicine, health-related quality of life (HRQOL) is constantly examined and according to the World Health Organization (WHOQOL Group), it includes the physical, psychical, social, and emotional spheres of life. ${ }^{3}$

De Walden Gałuszko defines quality of life as recognizing one's life at a particular moment. ${ }^{4}$ Quality of life is also dependent on the severity of disease, prognosis, methods of treatment, health conditions, side effects, and social isolation due to the necessity of hospitalization. Breast cancer treatment is possible thanks to the different surgical methods, radiotherapy, and chemotherapy directed toward lessening the probability of a relapse.

Research clearly demonstrates that diagnosis and treatment methods are likely to influence perceptible quality of life. The problems and symptoms faced by women with breast cancer may affect their psychical and mental condition. ${ }^{5}$ Radiotherapy is frequently used during the treatment of breast cancer. Women undergoing this therapy complain of a number of different ailments, including tiredness. ${ }^{6}$ The patient's therapeutic team is charged with easing such side effects by protective activities directed toward improvement of the patient's quality of life in every sphere of existence: biological, psychical, physical, social, and spiritual.

Analysis of the medical literature shows some reduction in patients' quality of life over the course of the treatment with radiotherapy. Some patients indicate an increased level of tiredness, which decreases their life quality. This research suggests that tiredness and cancer symptoms can increase during radiotherapy, but return to baseline at 7 months, suggesting that it is possible for patients to preserve a high quality of life. As such, medical interventions should focus on easing tiredness and other symptoms during radiotherapy. ${ }^{7}$ Other authors believe that fatigue, as an effect of cancer, appears along with pain, insomnia, and depression. ${ }^{8}$ Tiredness also has a negative influence on the family dynamics and the social lifestyle of the ill., ${ }^{9,10}$

The goal of the present study was to estimate the quality of life of patients with breast cancer who had undergone radiotherapy. Research questions focused on general quality of life after radiotherapy, tiredness during radiotherapy, and whether sociodemographic factors affect the quality of life.

\section{Methods}

\section{Sample}

The study included 120 women with breast cancer who were receiving postoperative adjuvant radiotherapy, 60 of them in an outpatient setting and the other 60 in a stationary setting.

Patients were informed about the aim and range of the research before they agreed to participate and provided signed consent. Tests were free of charge and voluntary. Each patient was instructed how to complete the questionnaire.

\section{Measurements and procedure}

Quality of life measurement was carried out on the basis of the Functional Assessment of Chronic Illness TherapyFatigue (FACIT-F) questionnaire (version 4), which consists of five parts:

- Physical well-being-seven questions

- Social/family well-being-seven questions

- Emotional well-being-six questions

- Functional well-being-seven questions

- Fatigue subscale-13 questions

The questionnaire includes a subscale of tiredness (13 points). Each question is rated according to a five-point Likert scale. The patients were evaluated in all the spheres of life and the results were summed up according to the accepted standard. A higher result means a higher level of well-being. ${ }^{11}$ The FACIT scale has been found to have superior internal validity (Cronbach's alpha $=0.96) .{ }^{12}$ The FACIT-F is characterized by a high level of test reliability $(r=0.90)$ and internal consistency $(\alpha=0.93-0.95) .{ }^{13}$ Fatigue ratings have demonstrated significant correlation with perceptible quality of life, especially among those with breast cancer. ${ }^{14}$ While various scales are recommended to estimate fatigue, the FACIT-F is highly rated due to its good psychometric properties.

The quality of life, daily functioning, and the state of fatigue were assessed at the end of third week of radiotherapy by using FACIT-F questionnaire. On the fatigue scale, scores range from 0 to 52 , where " 0 " means the highest level of fatigue and " 52 " means the lowest. The FACIT-F questionnaire has been previously demonstrated as a useful tool for rating 
the quality of life of women with breast cancer. ${ }^{15}$ In addition, medical documentation and sociodemographic data were taken into account.

\section{Ethical considerations}

Testing was carried out in the radiotherapy and teleradiotherapy centers of F Łukaszczyk Oncological Center in Bydgoszcz, Poland. This study was approved by the Bioethical Commission of Mikołaj Kopernik University in Torun, Poland and the Ludwik Rydygier Collegium Medicum in Bydgoszcz, Poland. As described, all participating patients provided informed consent.

\section{Data analysis}

Descriptive analyses were used for calculation of quantities and percentages in tables, including mean and standard deviation. The interdependence between two variables was assessed by determining Spearman's correlation coefficient $(R)$. The nonparametric Kruskal-Wallis test was used to compare numerous tests of independent groups. Results were considered statistically significant if the $P$-value was $\leq 0.05$. All statistical analyses were performed in the Statistica 10.0 program (StatSoft Cracow, Poland).

\section{Results}

\section{Descriptive analyses}

Among the 120 examined patients, there were 30 women aged between 20 and 50 years and the remaining were over 50 years of age, including 42 women who were 60 years of age or older. Most subjects had completed secondary education (48 people [40\%]) or a vocational degree (36 people [30\%]). Sixteen subjects (13.3\%) had a Master's degree. A vast majority of the subjects lived in cities (90 women [75\%]), with families (96 [80\%]), and the remaining were single (20\%). Seventy-nine women $(65.8 \%)$ were married while 41 were not. Self-reported material status was considered average by 94 women (78.3\%), high by $12(10 \%)$, and the remaining considered themselves to be living below the average standard. The most popular method of treatment was surgical, with operations performed on 114 women (47.5\%). Hormone therapy was used by 38 women (15.8\%). Twenty-seven patients were treated with one method, 66 received two methods, and 27 received three types of treatment.

During radiotherapy, there was an attempt to measure the quality of life. Table 1 presents the results of patients' HRQOL. General life quality was rated with 113.83 points and the average score for fatigue was 33.8 points.
Table I Quality of life in the study group according to FACIT-F $(\mathrm{N}=120)$

\begin{tabular}{lllllll}
\hline Item & PWB & SWB & EWB & FWB & FS & $\begin{array}{l}\text { FACIT-F } \\
\text { total score }\end{array}$ \\
\hline N=120 & $0-28$ & $0-28$ & $0-24$ & $0-28$ & $0-52$ & $0-160$ \\
Medium & 19.69 & 23.32 & 16.14 & 20.88 & 33.80 & 113.83 \\
SD & 5.553 & 4.209 & 4.171 & 5.006 & 9.846 & 23.652 \\
Confidence & 18.69 & 22.56 & 15.39 & 19.98 & 32.02 & 109.56 \\
-95\% & & & & & & \\
Confidence & 20.70 & 24.08 & 16.90 & 21.79 & 35.58 & 118.11 \\
+95\% & & & & & & \\
Min & 4.0 & 8.0 & 3.0 & 8.0 & 8.0 & 38.0 \\
Max & 28.0 & 28.0 & 24.0 & 28.0 & 52.0 & 160.0 \\
Q25 & 17.0 & 21.0 & 13.5 & 17.0 & 27.5 & 97.5 \\
Median & 20.0 & 24.0 & 16.0 & 22.0 & 33.0 & 116.5 \\
Q75 & 24.0 & 26.0 & 19.0 & 25.0 & 41.0 & 130.0 \\
\hline
\end{tabular}

Abbreviations: EWB, emotional well-being; FACIT-F, functional assessment of chronic illness therapy-fatigue; FS, fatigue subscale; FWB, functional well-being; Max, maximum; Min, minimum; PWB, physical well-being; SD, standard deviation; SWB, social/family well-being; Q25, lower quartile; Q75, upper quartile.

A significant difference was noticed in the assessment of the quality of life between the patients $\geq 71$ years of age and those between 61 and 70 years old. Older patients had a significantly higher quality of life (HRQOL 122.70 points, $P \leq 0.05$ ) (Table 2).

A lower level of fatigue was noticed among patients $\geq 71$ years of age and those under 50 years. The highest average score for fatigue was registered among those from 61 to 70 years of age $(P \leq 0.05)$ (Figure 1$)$.

The patients who indicated the lowest level of fatigue were those with a Master's degree and secondary education. Those who reported being the weariest were women with vocational education.

A slightly lower level of fatigue was reported by patients in a very good financial situation $(P=0.0008)$ (Figure 2 ).

A significantly higher life quality was indicated by patients with higher levels of education $(P=0.004)$ (Table 3$)$.

Again, a significantly higher life quality was noticed among wealthier patients $(P=0.0002)$ (Table 4$)$.

\section{Discussion}

Chronic cancer significantly influences the quality of life of patients treated with radiotherapy as it interferes with all the spheres of life. In the present study, quality of life was assessed among patients with breast cancer during radiotherapy using the standardized FACIT-F questionnaire. General evaluation of quality of life yielded 113.83 points.

Patients also estimated their fatigue using the fatigue subscale of the FACIT-F questionnaire. Some authors suggest that tiredness resulting from the disease influences the 
Table 2 HRQOL according to age

\begin{tabular}{lllllllllll}
\hline Age, years & $\mathbf{n}$ & Mean & SD & $\begin{array}{l}\text { Confidence } \\
-\mathbf{9 5 \%}\end{array}$ & $\begin{array}{l}\text { Confidence } \\
+\mathbf{9 5 \%}\end{array}$ & Min & Max & Q25 & Median & Q75 \\
\hline $30-50$ & 29 & 119.03 & 17.781 & 112.27 & 125.80 & 83.0 & 150.0 & 104.0 & 120.0 & 131.0 \\
$51-60$ & 49 & 113.92 & 21.122 & 107.85 & 119.99 & 71.0 & 160.0 & 97.0 & 116.0 & 124.0 \\
$61-70$ & 32 & 106.22 & 29.010 & 95.76 & 116.68 & 38.0 & 150.0 & 85.5 & 114.0 & 129.5 \\
$7 I$ and above & 10 & 122.70 & 27.467 & 103.05 & 142.35 & 79.0 & 160.0 & 98.0 & 128.0 & 146.0 \\
\hline
\end{tabular}

Abbreviations: HRQOL, health-related quality of life; Max, maximum; Min, minimum; SD, standard deviation; Q25, lower quartile; Q75, upper quartile.

quality of life more than any other symptom, including nausea, vomiting, pain, or depression. ${ }^{16}$ Tiredness is often hard to define and many patients with cancer suffer from insomnia. Both tiredness and lack of sleep limit everyday activities and affect the quality of life. In fact, despite them being individual terms, the two terms are usually used interchangeably. ${ }^{17}$

Several authors have reported results of comparative research extracting tiredness related to cancer and chronic fatigue and noting similar symptoms in patients with breast cancer and chronic fatigue. ${ }^{18}$

In the study of the quality of women's life, Courtier et al noticed the lowest score in the subscale FACIT-F in the third week of radiotherapy. ${ }^{19}$

Using particular techniques for coping with stress, such as a Chinese qigong that focuses on various techniques for enhancing life energy, can help the patients achieve recovery of their physical, psychical, and spiritual condition. ${ }^{20}$ Others have noticed a positive effect of special exercises among patients with advanced breast cancer, including improvement

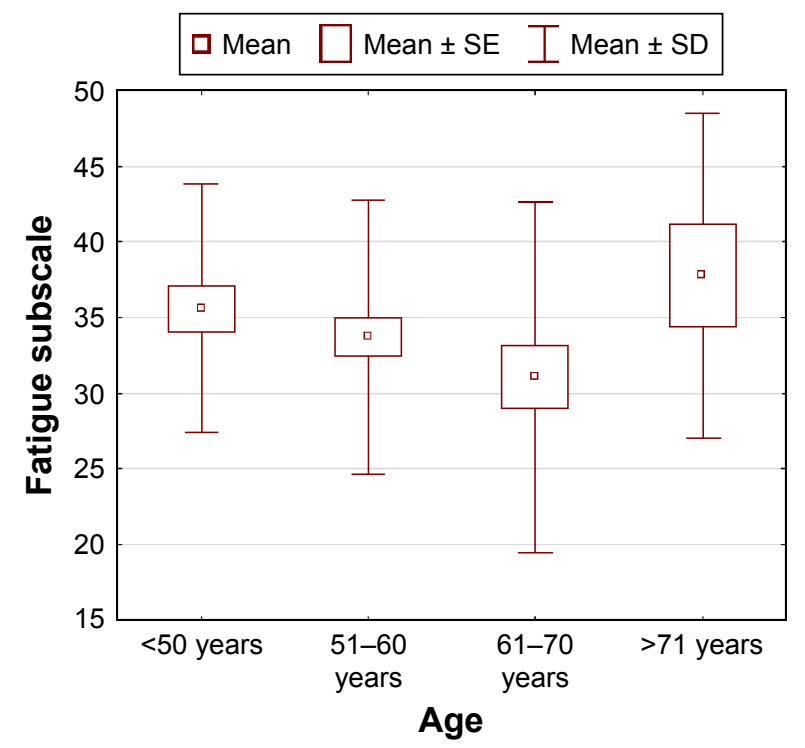

Figure I Fatigue subscale related to age.

Abbreviations: SD, standard deviation; SE, standard error. in physical well-being and a reduction of tiredness, as well as a higher quality of life. ${ }^{21}$

Cancer is a challenging experience in a person's life and contributes to psycho-physical changes concerning appearance, changes in well-being, fear, pain, and other outcomes. Reasonable psychological support is dependent on the individual patient's condition at a particular moment and must be selected by consideration of the patient's needs and expectations. As such, psychological support may take many different forms during cancer treatment, ranging from planned psychological consultations to intensive rehabilitation and psychotherapy. ${ }^{22}$

This research shows that breast cancer patients undergoing radiotherapy tended to estimate their emotional state quite high, which may indicate that these patients are in a position to rely on their families, friends, and medical staff to help them work through emotions. In addition, the respondents highly rated their quality of life in a daily routine. Therefore, it can be concluded that an active involvement in the process of treatment and care is necessary. Psychological support at

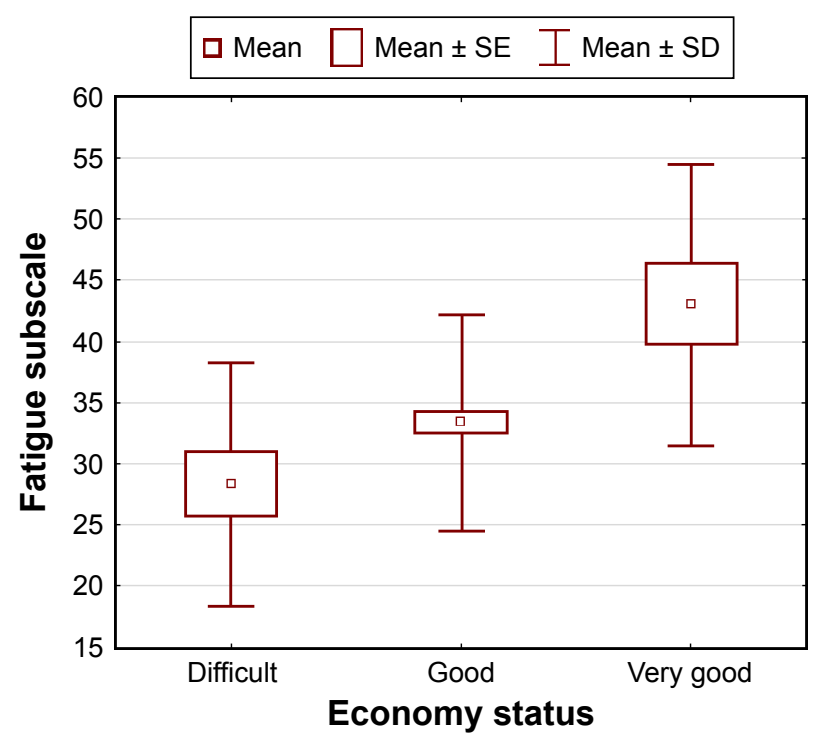

Figure 2 Fatigue subscale related to economy status. Abbreviations: SD, standard deviation; SE, standard error. 
Table 3 HRQOL according to educational level $(\mathrm{N}=120)$

\begin{tabular}{|c|c|c|c|c|c|c|c|c|c|c|}
\hline $\begin{array}{l}\text { Education } \\
\text { level }\end{array}$ & $\mathbf{n}$ & Mean & SD & $\begin{array}{l}\text { Confidence } \\
-95 \%\end{array}$ & $\begin{array}{l}\text { Confidence } \\
+95 \%\end{array}$ & Min & Max & Q25 & Median & Q75 \\
\hline Elementary & 20 & 108.45 & 21.603 & 98.34 & 118.56 & 55.0 & 146.0 & 95.5 & 112.0 & 123.5 \\
\hline Professional & 36 & 110.19 & 22.299 & 102.65 & 117.74 & 61.0 & 148.0 & 94.0 & 115.0 & 127.0 \\
\hline College & 48 & || $2.7 \mid$ & 25.776 & 105.22 & 120.19 & 38.0 & 160.0 & 99.0 & 113.0 & 126.5 \\
\hline High & 16 & 132.13 & 13.175 & 125.10 & 139.15 & 102.0 & 150.0 & 127.0 & 130.5 & 142.5 \\
\hline
\end{tabular}

Abbreviations: HRQOL, health-related quality of life; Max, maximum; Min, minimum; SD, standard deviation; Q25, lower quartile; Q75, upper quartile.

medical centers prepares the patient to deal with self-care and self-observation at home. It is also believed that a proper education and the help of psychologists ensure a patient's mental and physical safety.

Several sociodemographic factors were related to quality of life. For example, financial situation seems to be an important determinant affecting perceived quality of life. The findings show higher scores for quality of life in the wealthy and lower scores in patients who belong to middle and lower class. A family's financial situation can be impacted significantly by the costs associated with treatment and long-lasting therapy, ultimately impacting the socioeconomic conditions. To provide proper social care and to point out other sources of financial support, it is essential to recognize the social and material states of patients and their families.

Education is another important factor in determining the quality of life. The findings suggest that educated patients place high value on their life and cope well within different spheres of life.

Quality of life is also dependent on age. The reaction to illness is the result of individual resources, extra affection, and interpersonal contacts.

Patients aged 71 years and older and women aged 50 years reported higher quality of life than women between 51 and 70 years. We can assume that treatment by radiotherapy is well tolerated by patients.

In a previous study assessing the influence of breast cancer treatment on patients' HRQOL 5 years after treatment, the authors did not notice a relevant connection between treatment and quality of life in elderly women. In fact, as the appearance of lymphedema decreased, the quality of life significantly increased. ${ }^{23}$

Xiao et al reported in their study that QOL in women diagnosed early with breast cancer did not change or decrease significantly during or after radiotherapy. The authors noted the preradiation characteristics, including BMI and perceived stress, of those patients who may experience physical and mental disorders during and up to 1 year after radiotherapy. Data were measured by Medical Outcomes Study 36-Item Short Form, version $2 .{ }^{24}$

Radiotherapy is undoubtedly a progressive and improved method for the treatment of breast cancer. The advanced technique minimizes side effects while providing the greatest level of treatment. A professional and experienced therapeutic team can provide comprehensive medical care that meets all biological, psychical, social, and spiritual needs of the patient. Such an action improves the quality of life of the ill to a great extent.

\section{Conclusion}

HRQOL and the state of fatigue in patients treated with radiotherapy for breast cancer were influenced by age and other factors. Quality of life was classified as high among women aged 71 and above, while younger patients (51-70 years of age) had slightly lower scores. Patients with higher education presented with a remarkably better life quality than those with only primary education. Patients' quality of life was also related to their financial situation. The highest quality of life was reported by those with the greatest economic advantage.

Table 4 HRQOL according to economy status $(\mathrm{N}=120)$

\begin{tabular}{|c|c|c|c|c|c|c|c|c|c|c|}
\hline $\begin{array}{l}\text { Economy } \\
\text { status }\end{array}$ & $n$ & Mean & SD & $\begin{array}{l}\text { Confidence } \\
-95 \%\end{array}$ & $\begin{array}{l}\text { Confidence } \\
+95 \%\end{array}$ & Min & Max & Q25 & Median & Q75 \\
\hline Difficult & 14 & 105.50 & 23.320 & 92.04 & 118.96 & 55.0 & 147.0 & 90.0 & 105.5 & 121.0 \\
\hline Good & 94 & 112.03 & 21.874 & 107.55 & $|16.5|$ & 38.0 & 160.0 & 97.0 & 115.5 & 126.0 \\
\hline Very good & 12 & 137.67 & 25.065 & 121.74 & 153.59 & 64.0 & 156.0 & 132.0 & 146.5 & 151.5 \\
\hline
\end{tabular}

Abbreviations: HRQOL, health-related quality of life; Max, maximum; Min, minimum; SD, standard deviation; Q25, lower quartile; Q75, upper quartile. 


\section{Acknowledgments}

The authors would like to thank all the participants of the test and the nurses who supported them during the research.

\section{Author contributions}

$\mathrm{MM}$ contributed to the conception and the study design, conducted statistical analysis and interpretation of data, was responsible for drafting of the manuscript, and supervised the study. MKP contributed to the study design, acquisition of data, and analysis and interpretation of data, and made critical revisions to the paper for important intellectual content. KKK and JR contributed to analysis and interpretation of data and made critical revisions to the paper for important intellectual content. All the authors also read and gave their final approval of the version to be published.

\section{Disclosure}

The authors report no conflicts of interest in this work.

\section{References}

1. Breast cancer in women (C50) [webpage on the Internet]. Krajowy Rejestr Nowotworów. Available from: http://onkologia.org.pl/nowotwory-piersikobiet/. Accessed September 23, 2016.

2. Didkowska J. Epidemiologia Nowotworów Złośliwych w Polsce. [Epidemiology of Malignant Tumors in Poland]. Warsaw: National register of cancer; 2011.

3. WHOQOL Group. Study protocol for the world health organization project to develop a quality of life assessment instrument (WHOQOL). Qual Life Res. 1993;2(2):153-159.

4. De Walden Gałuszko K. The problem of quality of life in terminal patients. Medipress. Palliative Med. 2003;1:4-6.

5. Groenvold M. Health-related quality of life in early breast cancer. Dan Med Bull. 2010;57(9):B4184.

6. Wayne A, Bardwell WA, Ancoli-Israel S. Breast cancer and fatigue. Sleep Med Clin. 2008;3(1):61-71.

7. Lee TS, Kilbreath SL, Refshauge KM, Pendlebury SC, Beith JM, Lee MJ. Quality of life of women treated with radiotherapy for breast cancer. Support Care Cancer. 2007;16(4):399-405.

8. Barton-Burke M. Cancer-related fatigue and sleep disturbances. Further research on the prevalence of these two symptoms in long-term cancer survivors can inform education, policy, and clinical practice. Am J Nurs. 2006; 106(3 Suppl):72-77.
9. Cella D, Davis K, Breitbart W, Curt G. Cancer-related fatigue: prevalence of proposed diagnostic criteria in a United States sample of cancer survivors. J Clin Oncol. 2001;19(14):3385-3391.

10. Ancoli-Israel S, Liu L, Marler MR, et al. Fatigue, sleep, and circadian rhythms prior to chemotherapy for breast cancer. Support Care Cancer. 2006;14(3):201-209.

11. Webster K, Cella D, Yost K. The functional assessment of chronic illness therapy (FACIT) measurement system: properties, application, and interpretation. Health Qual Life Outcomes. 2003;1(1):79-86.

12. Chandran V, Bhella S, Schentag C, Gladman D. Functional assessment of chronic illness therapy-fatigue scale is valid in patients with psoriasis arthritis. Ann Rheum Dis. 2007;66(7):936-939.

13. Cella D. Manual of the Functional Assessment of Chronic Illness Therapy (FACIT) measurement system. Evanston, IL: Evanston Northwestern Healthcare and Northwestern University; 1997.

14. Cella D, Yount S, Sorensen M, Chartash E, Sengupta N, Grober J. Validation of the functional assessment of chronic illness therapy fatigue scale relative to other instrumentation in patients with rheumatoid arthritis. J Rheumatol. 2005;32(5):811-819.

15. Reimer T, Gerber B. Quality-of-life considerations in the treatment of early-stage breast cancer in the elderly. Drugs Aging. 2010;27(10): 791-800.

16. Curt GA, Breitbart $\mathrm{W}$, Cella $\mathrm{D}$, et al. Impact of cancer-related fatigue on the lives of patients: new findings from the fatigue coalition. Oncologist. 2000;5(5):353-360.

17. Ancoli-Israel S, Moore PJ, Jones V. The relationship between fatigue and sleep in cancer patients: a review. Eur J Cancer Care (Engl). 2001;10(4): 245-255.

18. Bennett B, Goldstein D, Friedlander M, Hickie I, Lloyd A. The experience of cancer-related fatigue and chronic fatigue syndrome: a qualitative and comparative study. J Pain Symptom Manage. 2007; 34(2):126-135.

19. Courtier N, Gambling T, Enright S, Barrett-Lee P, Abraham J, Mason MD. A prognostic tool to predict fatigue in women with early-stage breast cancer undergoing radiotherapy. Breast. 2013;22(4):504-509.

20. Zhen Chen, Zhiqiang Meng, Milbury K, et al. Qigong improves quality of life in women undergoing radiotherapy for breast cancer: results of a randomized controlled trial. Cancer. 2013;119(9):1690-1698.

21. Sarkar SK, Manir KS, Bhadra K, Kumar G, Manna A, Patra NB. Fatigue in breast cancer patients on adjuvant treatment: course and prevalence. Indian J Palliat Care. 2012;18(2):109-116.

22. Cieślak K. Professional psychological support and psychotherapy methods for oncology patients. Basic concepts and issues. Rep Pract Oncol Radiother. 2013;18(3):121-126.

23. Neuner JM, Zokoe N, McGinley EL, et al. Pezzin. quality of life among a population-based cohort of older patients with breast cancer. Breast. 2014;23(5):609-616.

24. Xiao C, Miller AH, Jennifer Felger J, Mister D, Liu T, Torres MA. A prospective study of quality of life in breast cancer patients undergoing radiation therapy. Adv Radiat Oncol. 2016;1(1):10-16.
Clinical Interventions in Aging

\section{Publish your work in this journal}

Clinical Interventions in Aging is an international, peer-reviewed journal focusing on evidence-based reports on the value or lack thereof of treatments intended to prevent or delay the onset of maladaptive correlates of aging in human beings. This journal is indexed on PubMed Central, MedLine,

\section{Dovepress}

CAS, Scopus and the Elsevier Bibliographic databases. The manuscript management system is completely online and includes a very quick and fair peer-review system, which is all easy to use. Visit http://www.dovepress. com/testimonials.php to read real quotes from published authors. 